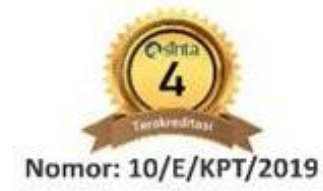

INFORMASI ARTIKEL

Received: August, 21, 2019

Revised: July, 11, 2021

Available online: July, 12, 2021

at : http://ejurnalmalahayati.ac.id/index.php/holistik

\title{
Pengaruh terapi musik klasik (mozart) terhadap tekanan darah pada lansia dengan hipertensi
}

\author{
Rahma Elliya ${ }^{1}$, Satria Baharuddin ${ }^{2 *}$, Dessy Hermawan ${ }^{1}$
}

${ }^{1}$ Program Studi IImu Keperawatan, Fakultas Kedokteran Universitas Mahalayati.

${ }^{2}$ Posyandu Lansia Puskesmas Kalibalagan Kabupaten Lampung Utara

Korespondensi Penulis: Satria Baharuddin. Email: satriabaharudddin@gmail.com

\section{Abstract \\ The effect of classic music therapy (mozart) on blood pressure in elderly with hypertension}

Background: Based on the Health Profile of North Lampung Regency in 2018 the number of people with hypertension in the last three years increased to 600 in 2017 and in 2018 the number of sufferers was 741 sufferers.

Purpose: To determine the effect of classical music therapy (Mozart) on blood pressure.

Method: Quantitative research uses a quasi-experimental approach. The population was patients with hypertension at the Elderly Post health service (Posyandu) at Kalibalangan Health Center, which amounts to 80 people. A sample of 62 participants divided into 2 groups, 31 participants by music therapy + antihypertensive drug (amlodipine), and 31 other participants only take the antihypertensive drug as amlodipine. Data collection techniques by monitoring of blood pressure. The statistical test used is the Independent Test.

Results: The average blood pressure of systole before being given Classical Music (Mozart) + Amlodiphine is $164.2 \mathrm{mmHg}$, diastole $102.7 \mathrm{mmHg}$. The average blood pressure of systole before being given Amlodipine is $163.5 \mathrm{mmHg}$, diastole $103.9 \mathrm{mmHg}$. Average blood pressure of systole after given Classical Music (Mozart) + Amlodipine is $147.1 \mathrm{mmHg}$, diastole $89.03 \mathrm{mmHg}$. The mean systole blood pressure after Amlodipine is $152.3 \mathrm{mmHg}$, diastole $95.2 \mathrm{mmHg}$. There are differences in systolic blood pressure in patients with moderate hypertension between the intervention groups (classical music therapy (mozart) ) and the control group ( $p$-value = $0,000)$ There is a difference in diastolic blood pressure in patients with moderate hypertension between the intervention group (classical music therapy (mozart) and the control group ( $p$ value $=0.016$ ).

Conclusion: There is an influence of classical music therapy (mozart) on blood pressure, it is recommended to use the results of this study as an alternative therapy in the treatment of primary hypertension and so that it can be socialized to the community

\section{Keywords: Classical Music Therapy (Mozart); Blood Pressure; Hypertension; Elderly}

Pendahuluan: Jumlah penderita hipertensi di Kabupaten Lampung Utara dalam tiga tahun terakhir mengalami peningkatan tahun 2015 sebesar 10.743 penderita tahun 2016 sebesar 13.039 penderita dan tahun 2017 sebesar 11.228 penderita. Sementara di Puskesmas Kalibalangan tahun 2015 sejumlah 604 turun menjadi 458 tahun 2016, kemudian meningkat menjadi 600 tahun 2017 dan tahun 2018 sejumlah 741 pasien, musik klasik merupakan salah satu terapi non farmakalogik yang mampu menurunkan tekanan darah. 
Pengaruh terapi musik klasik (mozart) terhadap tekanan darah pada lansia dengan hipertensi

Tujuan: Diketahui pengaruh terapi music klasik (Mozart) terhadap tekanan darah pada lansia.

Metode: Penelitian kuantitatif menggunakan pendekatan eksperimen semu. Populasi dalam penelitian ini adalah penderita hipertensi di Posyandu Puskesmas Kalibalangan yang berjumlah 80 orang. Sampel sebanyak 62 partisipan dibagi menjadi 2 kelompok, 31 partisipan dengan terapi musik + obat anti hipertensi (amlodipine), dan 31 partisipan lainnya hanya mengkonsumsi obat anti hipertensi sebagai amlodipine. Teknik pengumpulan data dengan mengamati tekanan darah. Uji statistik yang digunakan adalah Independent Test.

Hasil: Rata-rata tekanan darah systole sebelum diberi Musik Klasik (Mozart) + Amlodiphine adalah $164.2 \mathrm{mmHg}$, diastole $102,7 \mathrm{mmHg}$, pada kelompok yang diberi Amlodipine adalah $163.5 \mathrm{mmHg}$, diastole $103.9 \mathrm{mmHg}$. Ratarata tekanan darah systole sesudah diberi Musik Klasik (Mozart) + Amlodipine adalah $147.1 \mathrm{mmHg}$, diastole $89.03 \mathrm{mmHg}$, pada kelompok yang diberi Amlodipine adalah $152.3 \mathrm{mmHg}$, diastole $95.2 \mathrm{mmHg}$. Ada perbedaan tekanan darah sistolik pada penderita hipertensi sedang antara kelompok intervensi (terapi music klasik (mozart) dan kelompok control $(p$-value $=0,000)$. Ada perbedaan tekanan darah diastolic pada penderita hipertensi sedang antara kelompok intervensi (terapi music klasik (mozart) dan kelompok control ( $p$ value $=0,016$ ).

Simpulan: Ada pengaruh terapimusik klasik (Mozart) terhadap tekanan darah pada lansia, sehingga disarankan agar menggunakan hasil penelitian ini sebagai salah satu terapi alternative dalam pengobatan hipertensi primer dan agar dapat disosialisasikan kepada masyarakat.

\section{Kata Kunci:Terapi music klasik (Mozart); Tekanan darah; Hipertensi; Lansia}

\section{PENDAHULUAN}

Saat ini terdapat 600 juta penderita hipertensi di seluruh dunia dan 3 juta di antaranya meninggal setiap tahunnya. Pada tahun 2000 , lebih dari $25 \%$ populasi dunia adalah penderita hipertensi (sekitar 1 miliar orang) dan dua pertiga dari penderita hipertensi tersebut berada di negara berkembang (Rahajeng\& Tuminah , 2009). Bila tidak dilakukan upaya yang tepat, jumlah ini akan terus meningkat. Pada tahun 2025 yang akan datang, jumlah penderita hipertensi di seluruh dunia diperkirakan akan meningkat menjadi $29 \%$ atau sekitar 1,6 miliar orang (Tedjasukmana, 2012).

Secara nasional terjadi peningkatan prevalensi hipertensi berdasarkan wawancara (apakah pernah didiagnosis nakes dan minum obat hipertensi) dari 7,6 persen pada tahun 2007 menjadi 9,5 persen pada tahun 2013. Prevalensi hipertensi di provinsi Lampung berdasarkan hasil pengukuran tekanan darah yaitu $24,7 \%$. Sedangkan prevalensi hipertensi provinsi Lampung berdasarkan diagnosis tenaga kesehatan adalah $7,4 \%$, ditambah kasus yang minum obat hipnertensi prevalensi hipertensi berdasarkan wawancara sedikit bertambah menjadi 7,6\% (Kementrian Kesehatan Republik Indonesia, 2012). Dari 10 besar penyakit terbanyak di provinsi Lampung, pada tahun 2010 hipertensi menduduki urutan ketujuh dengan jumlah5.29\% dan meningkat menjadi urutan kelima pada tahun 2011 dengan jumlah 7.05\% dan pada tahun 2012 hipertensi meningkat lagi menjadiurutan ketiga dengan jumlah $11,01 \%$ (SP2TP, 2012), dan pada tahun 2014 meningkat menjadi urutan pertama yaitu $30.01 \%$ (Dinas Kesehatan Provinsi Lampung, 2015). Sedangkan untuk Kabupaten Lampung Utara menempati urutan kedua dengan prevalensi $70,99 \%$.

Berdasarkan profil kesehatan Kabupaten Lampung Utara tahun 2018 diketahui bahwa jumlah penderita hipertensi dalam tiga tahun terakhir mengalami fluktuasi yaitu 10.743 pada tahun 2015, meningkat menjadi 13.039 kasus pada tahun 2016 dan kembali turun hingga 11.228 kasus pada tahun 2017.

Berdasarkan profil kesehatan Puskesmas Kalibalangan angka kejadian hipertensi sejumlah 604 pada tahun 2015, turun menjadi 458 pada tahun 2016, kemudian meningkat menjadi 600 pada tahun 2017, dan 2018 jumlah penderita hipertensi mencapai 741 pasien.

Tekanan darah tinggi dalam jangka panjang waktu lama akan merusak endothel arteri dan mempercepat arterioklorosis. Bila penderita memiliki factor risiko kardiovaskular lain, maka akan meningkatkan mortalitas dan morbiditas

\footnotetext{
Rahma Elliya', Satria Baharuddin ${ }^{2 *}$, Dessy Hermawan'

'Program Studi llmu Keperawatan, Fakultas Kedokteran Universitas Mahalayati.

${ }^{2}$ Posyandu Lansia Puskesmas Kalibalagan Kabupaten Lampung Utara

Korespondensi Penulis: Satria Baharuddin. Email: satriabaharudddin@gmail.com
}

DOI: https://doi.org/10.33024/hjk.v15i1.1605 
Pengaruh terapi musik klasik (mozart) terhadap tekanan darah pada lansia dengan hipertensi

akibat gangguan kardiovaskularnya tersebut. Menurut Studi Farmingham, pasien dengan hipertensi mempunyai peningkatan risiko yang bermakna untuk penyakit koroner, stroke, penyakit arteri perifer, dan gagal jantung (Masriadi, 2016).

Penderita hipertensisebanyak $50 \%$ yang diketahui, $25 \%$ mendapat pengobatan dan hanya $12,5 \%$ yang diobati dengan baikjenis obat antihipertensi untuk terapi farmakologis hipertensi dianjurkan oleh JNC 7 adalah diuretika (Yogiantoro, 2015). Akan tetapi Pengobatan penderita hipertensi belum efektif karena sering terjadi kekambuhan serta menimbulkan efek samping berbahaya dalam jangka waktu yang panjang.Sehinggamenimbulkankomplikasihiperten siseperti stroke, translanteischemi attack, demensia vascular,penyakit jantung hipertensif(Arif, 2014), Hal inilah yang mendorong para ilmuwan untuk mengembangkan terapi non farmakologis. Terapi non farmakologis dapat digunakan sebagai pelengkap untuk mendapatkan efek pengobatan farmakologis (obat anti hipertensi) yang lebih baik. Beberapa penelitian telah membuktikan bahwa penatalaksanaan nonfarmakologis merupakan intervensi yang baik dilakukan pada setiap pengobatan hipertensi (Hikayati, Flora \& Purwanto, 2014).

Sejauh penatalaksanaan farmakologis dapat menghambat system sipatiko-adrenergik diupayakan penatalaksanaan hipertensi umumnya dilakukan dengan mengatasi gaya hidup seperti pengurangan berat badan, pengaturan diet makanan, olah raga teratur dan mengurangi stres. Rangkaian ini merupakan tatalaksana nonfarmakologis. Pengaturan diet makanan dan olah raga teratur umumnya telah terbukti dapat menurunkan tekanan darah namun penggunaan music klasik (mozart) sebagai tatalaksana nonfarmakologis masih dalam tahap perkembangan (Sastra. 2011).

Terapi musik untuk mengatasi berbagai masalah dalam aspek fisik, psikologis, kognitif dan kebutuhan sosial individu uang mengalami cacat fisik. (Salim, 2011)Dan jugaTerapi musikmetode penyembuhan dengan musik melalui energy yang dihasilkan dari musik itu sendiri (Natalina, 2013).
Dalam terapi musik diketahui bahwa rangsangan musik ternyata mampu mengaktivasi sistem limbik yang berhubungan dengan emosi. Saat sistem limbik teraktivasi, otak menjadi rileks, kondisi inilah yang memicu tekanan darah menurun. Dalam Terapi musik, Alunan musik juga dapat menstimulasi tubuh untuk memproduksi molekul nitric oxide (NO). Molekul ini bekerja pada tonus pembuluh darah yang dapat mengurangi tekanandarah(Suherly, 2012).danjugaterapi musik memiliki kontribusi yang besar dan mengikuti ritme tubuh dan jiwa sejalan dengan harmoni yang dikeluarkannya (Novita, 2012).

Terapi music cenderung merangsang jantung, paru-paru dan emosi. Bunyi dari music yang bergetar membentuk pola dan menciptakan medan energy resonansi dan gerakan di ruang sekitarnya. Energy akan diserap oleh tubuh secara halus mengubah pernafasan, detak jantung, tekanan darah, ketegangan otot. Terapi music terbukti efektif dalam menurunkan tekanan darah (Triyanto, 2014).

Musik klasik diproduksi dalam seni, atau berakar dalam, tradisi musik liturgi Barat dan sekuler, yang mencakup periode yang luas, Musik klasik mozart memberikan ketenangan, memperbaiki persepsi sosial, dan memungkinkan pasien untuk berkomunikasi baik dengan hati maupun pikiran dan tidak mempunyai kesederhanaan yang polos seperti nyanyian Gregorian (Chambell, 2006; Mahanani, 2013).

Berdasarkan hasil pre survey diketahui bahwa selama ini Puskesmas Kalibalangan, petugas kesehatan hanya memberikan terapi farmakologi dalam menangani pasien hipertensi yaitu dengan pemberian obat-obatan, sedangkan terapi non farmakologi yang dianjurkan antara lain yaitu dengan menggunakan obat herbal seperti mengkonsumsi mentimun, rebusan daun salam. Sedangkan untuk terapi music belum pernah digunakan.

Hasil wawancara yang peneliti lakukan terhadap 10 penderita hipertensi diketahui bahwa 8 dari 10 penderita hipertensi $(80 \%)$ tidak mengetahui adanya terapi non farmakologis seperti terapi musik, yang mereka ketahui adanya terapi non farmakologi berupa rebusan mentimun seperti

\footnotetext{
Rahma Elliya', Satria Baharuddin ${ }^{2 *}$, Dessy Hermawan'

'Program Studi llmu Keperawatan, Fakultas Kedokteran Universitas Mahalayati.

${ }^{2}$ Posyandu Lansia Puskesmas Kalibalagan Kabupaten Lampung Utara

Korespondensi Penulis: Satria Baharuddin. Email: satriabaharudddin@gmail.com
}

DOI: https://doi.org/10.33024/hjk.v15i1.1605 
Pengaruh terapi musik klasik (mozart) terhadap tekanan darah pada lansia dengan hipertensi

yang dijelaskan oleh petugas kesehatan melalui penyuluhan, namun belum pernah mempraktikkannya.

\section{METODE}

Jenis penelitian kuantitatif, dilakukandi Posyandu Lansia Puskesmas Kalibalangan Lampung Utara selama satu bulan yaitu padabulan Juni-Juli 2019 dengan menggunakan pendekatan quasi eksperimen. Populasinya lansia penderita hipertensi dan sampelnya sebanyak 62 partisipan yang dibagi menjadi 2 kelompok kelompok 1 adalah kelompok intervensi yaitu sebanyak 31 partisipan yang diberi terapi musik, dan kelompok 2 adalah kelompok kontrol yaitu yang tidak diberi terapi musik (hanya mengkonsumsi obat antihipertensi). Variabel independen music klasik Mozart, sedangkan variabel dependen tekanan darah. Analisa data yang digunakan untuk melihat pengaruh terapi musik klasik (mozart) terhadap tekanan darah sistolik dan diastolik pada penderita hipertensi sedang, analisis bivariatdilakukan dengan cara: Uji t-Independen.

Pertemuan petama, dimulai dengan menjelaskan manfaat terapi music dan prosedur penelitian selama 5 menit, kemudian dilakukan pengukuran tekanan darah selama 5 menit lalu Musik mulai diperdengarkan selama 30 menit dimulai sejak tombol play pada Handphone ditekan (dihitung dengan stopwatch). Partisipan dianjurkan untuk meneruskan terapi keesokan harinya pada jam yang sama (satu hari satu kali) dan Pengukuran tekanan darahs elama 5 menit pada minggu kedua, ketiga dan keempat. Kemudian partisipan mendengarkan music selama 30 menit dan Pemberian intervensi dilakukan setiap pagi hari 07.00-08.00 yang diawasi oleh anggota keluarga yang telah diberi edukasi sebelumnya. Selama intervensi partisipan tetap mengkonsumsi terapi farmakologi berupa amlodiphine $2.5 \mathrm{mg}$, yang diberikan $1 \mathrm{x}$ perhari pada pagi hari kemudian dalam pelaksanaan penelitian ini peneliti dibantu oleh 2 orang asisten yang memiliki tingkat pendidikan yang sama dengan peneliti(mahasiswa keperawatan). Masing-masing asisten bertanggungj awab terhadap 10 sampel sedangkan peneliti bertanggung jawab terhadap 11 sampel kelompok intervensi dan 31 sampel kelompok control sedangkan pada kelompok control hanya diberi terapi farmakologi berupa amlodiphine $2.5 \mathrm{mg}$ yang diberikan $1 \mathrm{x}$ perhari pada pagi hari sesuai dengan etiket yang diberikan oleh puskesmas. Pengukuran tekanan darah pada kelompok intervensi maupun kelompok control dilakukan setiap minggu setengah jam setelah terapi music klasik, dimulai pada hari ke-1, ke-8, ke-15, ke-22 dan ke-29 untuk membandingkan penurunan antara kedua kelompok tersebut.

\section{HASIL}

Tabel1.DistribusiFrekuensiKarakteristik Partisipan BerdasarkanUsia dan Jenis KelaminN=62

\begin{tabular}{lcc}
\hline \multicolumn{1}{c}{ Karakteristik } & Jumlah & Persentase (\%) \\
\hline Usia & 16 & \\
- Lansia Awal (46-55 Tahun) & 46 & 25.8 \\
- Lansia Akhir (56-65 Tahun) & & 74.2 \\
Jenis Kelamin: & 32 & 51.6 \\
$-\quad$ Laki-laki & 30 & 48.4 \\
\hline$\quad$ Perempuan & & \\
\hline
\end{tabular}

Berdasarkan Tabel 1. diketahui bahwa sebagian besar partisipan dalam rentang usialansia akhir (56-65 Tahun) yaitu sebanyak 46 partisipan (74.2\%), dan berdasarkan jenis kelamin lebih dari separuh partisipan berjenis kelamin laki-laki yaitu sebanyak 32 partisipan (51.6\%).

\footnotetext{
Rahma Elliya', Satria Baharuddin²*, Dessy Hermawan'

'Program Studi llmu Keperawatan, Fakultas Kedokteran Universitas Mahalayati.

${ }^{2}$ Posyandu Lansia Puskesmas Kalibalagan Kabupaten Lampung Utara

Korespondensi Penulis: Satria Baharuddin. Email: satriabaharudddin@gmail.com
}

DOI: https://doi.org/10.33024/hjk.v15i1.1605 
Pengaruh terapi musik klasik (mozart) terhadap tekanan darah pada lansia dengan hipertensi

Tabel 2. Perbandingan Tekanan Darah Pada Kedua Kelompok N= 62

\begin{tabular}{|c|c|c|}
\hline Tekanan Darah & Musik Klasik (Mozart) + Amlodipine $(n=31)$ & Amlodipine ( $n=31)$ \\
\hline \multicolumn{3}{|c|}{ Sebelum Intervensi (Mean $\pm S D$ ) } \\
\hline \multicolumn{3}{|c|}{ Rentang $(\mathrm{mmHg})$} \\
\hline Sistole & $164.2 \pm 5.02(160-170)$ & $163.5 \pm 4.86(160-170)$ \\
\hline Diastole & $102.7 \pm 5.75(100-120)$ & $103.9 \pm 4.95(100-110)$ \\
\hline \multicolumn{3}{|c|}{ Sesudah Intervensi (Mean $\pm S D$ ) } \\
\hline Sistole & $147.1 \pm 6.43(140-160)$ & $152.3 \pm 6.2(140-160$ \\
\hline Diastole & $89.03 \pm 5.39(80-100)$ & $95.2 \pm 9.30(80-110)$ \\
\hline
\end{tabular}

Tabel diatas didapatkan bahwa rata-rata tekanan darah systole sebelum diberi Musik Klasik (Mozart) adalah $164.2 \mathrm{mmHg}$ dengan standar deviasi $5,04 \mathrm{mmHg}$, dengan tekanan darah systole terendah $160 \mathrm{mmHg}$ dan tertinggi $170 \mathrm{mmHg}$, sedangkan untuk rata-rata tekanan darah diastole sebelum diberi Musik Klasik (Mozart) adalah 102,7 mmHg dengan standar deviasi 5,85, dengan tekanan darah distole terendah 100 dan tertinggi 120 .

Tabel diatas didapatkan bahwa rata-rata tekanan darah systole sesudah diberi Musik Klasik (Mozart) + Amlodipine adalah $147.1 \mathrm{mmHg}$ dengan standar deviasi $6,43 \mathrm{mmHg}$, dengan tekanan darah systole terendah $140 \mathrm{mmHg}$ dan tertinggi $160 \mathrm{mmHg}$, sedangkan untuk rata-rata tekanan darah diastole sesudah diberi Musik Klasik (Mozart) + Amlodipine adalah $89.03 \mathrm{mmHg}$ dengan standar deviasi 5.39, dengan tekanan darah distole terendah 80 dan tertinggi 100.

Pada kelompok (hanya obat Amlodipine), rata-rata tekanan darah systole sebelum diberi Amlodipine adalah $163.5 \mathrm{mmHg}$ dengan standar deviasi $4,86 \mathrm{mmHg}$, dengan tekanan darah systole terendah $160 \mathrm{mmHg}$ dan tertinggi $170 \mathrm{mmHg}$, sedangkan untuk rata-rata tekanan darah diastole sebelum diberi Amlodipine adalah 103.9 mmHg dengan standar deviasi $4.95 \mathrm{mmHg}$, dengan tekanan darah distole terendah 100 dan tertinggi 110 .

Tabel diatas didapatkan bahwa rata-rata tekanan darah systole sesudah diberi Amlodipine adalah 152.3 $\mathrm{mmHg}$ denganstandardeviasi $6,2 \mathrm{mmHg}$, dengan tekanan darah systole terendah $140 \mathrm{mmHg}$ dan tertinggi 160 $\mathrm{mmHg}$, sedangkan untuk rata-rata tekanan darah diastole sesudah diberi Amlodipine adalah $95.2 \mathrm{mmHg}$ dengan standar deviasi $9.3 \mathrm{mmHg}$, dengan tekanan darah diastole terendah 80 dan tertinggi 110 .

Tabel 3.Pengaruh Terapi Musik Klasik (Mozart) terhadap tekanan darah sistolik pada lansia

\begin{tabular}{lccc}
\hline Variabel & Mean Rank & Sum of Rank & $p$-value \\
& & & \\
\hline Sistolik: & 39.05 & 1210.5 & $\mathbf{0 . 0 0 0}$ \\
Musik Klasik (Mozart)+Amlodipine & 23.95 & 742.5 & \\
Hanya Amlodipine & & & \\
& 36.63 & 1135.5 & $\mathbf{0 . 0 1 6}$ \\
Diastolik: & 26.37 & 817.5 & \\
Musik Klasik (Mozart)+ Amlodipine & & \\
Hanya Amlodipine & & \\
\hline
\end{tabular}

Berdasarkan tabel 3. diketahui bahwa hasil uji statistik di atas didapatkan $p$-value $=0,000$, maka dapat disimpulkan ada pengaruh terapi musik klasik (Mozart) terhadap tekanan darah sistolik pada lansia. Hasil uji

\footnotetext{
Rahma Elliya', Satria Baharuddin ${ }^{2 *}$, Dessy Hermawan'

'Program Studi llmu Keperawatan, Fakultas Kedokteran Universitas Mahalayati.

${ }^{2}$ Posyandu Lansia Puskesmas Kalibalagan Kabupaten Lampung Utara

Korespondensi Penulis: Satria Baharuddin. Email: satriabaharudddin@gmail.com

DOI: https://doi.org/10.33024/hjk.v15i1.1605
} 
statistik pada diastolik didapatkan $p$-value $=$ 0,016, maka dapat disimpulkan ada pengaruh terapi musik klasik (Mozart) terhadap tekanan darah diastolik pada lansia.

\section{PEMBAHASAN}

Hasil penelitian menunjukkan ada pengaruh terapi musik klasik (Mozart) terhadap tekanan darah sistolik pada lansia. ( $p$ value 0,000 ) dan ada pengaruh terapi musik klasik (Mozart) terhadap tekanan darah diastolik pada lansia ( $p$ value 0,016).

Hasil penelitian ini sejalan dengan teori bahwa dalam hal penurunan tekanan darah dan stres diduga bahwa konsentrasi katekolamin plasma mempengaruhi aktivasi simpatoadrenergik, dan juga menyebabkan terjadinya pelepasan stressreleased hormones. Pemberian musik dengan irama lambat akan mengurangi pelepasan katekolamin kedalam pembuluh darah, sehingga konsentrasi katekolamin dalam plasma menjadi rendah. Hal ini mengakibatkan tubuh mengalami relaksasi, denyut jantung berkurang dan tekanan darah menjadi turun.

Hasil penelitian ini didukung oleh pendapat para pakar kesehatan di New Orleans juga mengungkap, terapi musik selama 30 menit sehari mampu menggantikan terapi obat-obatan hipertensi. Rangsangan musik ternyata mampu mengaktivasi sistem limbik yang berhubungan emosi. Saat sistem limbic teraktivasi, maka individu tersebut menjadi rileks, saat keadaan inilah tekanan darah mulai turun. Selain itu pula, alunan musik juga dapat menstimulasi tubuh untuk memproduksi molekul nitric oxide (NO). Molekul ini bekerja pada tonus pembuluh darah yang dapat menurunkan tekanan darah (Mulyadi, 2013).

Penelitian ini sejalan dengan penelitiansebelumnyadenganhasil analisis t-test dan Wilcoxon didapatkan pengaruh musik klasik terhadap penurunan tekanan darah lansia penderita hipertensi ( $p$ value $=0,000)(\alpha=0,005)$. Maka kesimpulannya adalah terdapat pengaruh mendengarkan musik klasik terhadap penurunan tekanan darah pada lansia penderita hipertensi (Mahatidanar, 2016)
Musik mempengaruhi persepsi dengan 3 cara: Pertama dengan distraksi yaitu pengalihan pikiran dan kosentrasi pada hal-hal yang menyenangkan, kedua dengan relaksasi, musik menyebabkan pernafasan lebih rileks dan menurunka denyut jantung, ketiga dengan menciptakan rasa nyaman, music dapat menurunkan kadar kortisol yang meningkat pada saat stres, musik jugamerangsang pelepasan endorfin, yaitu hormon tubuh yang memberikan perasaan senang dan nyaman. Musik yang diperdengarkan pada penderita hipertensi akan diterima oleh sistem pendengaran yang secara garis besar meliputi membran timpani, maleus, incus, stapes dan vestibuli serta koklea. Telinga mengubah gelombang bunyi di luar menjadi potensial aksi di nervus auditorius. Bunyi dikirimkan sebagai impuls Menuju ke korteks auditorius yaitu di korteks pendengaran primer area brodman 41 di bagian superior lobus temporalis. Dari semua bagian korteks lobus temporal sebagai area asosiasi auditorius, sinyal neurohormonal diterima oleh amigdala. Di amigdala sinyal kembali dijalarkan ke (1) area korteks yang sama yaitu kortek asosiasi auditorius (2) ke hipokampus, (3) septum, (4) ke talamus dan (5) khususnya ke hipotalamus.

Hipotalamusdimanapusat berbagai mekanisme tubuh sehingga stimulasi musik pada hipotalamus akan memberikan efek sebagai berikut (1) penurunan tekanan arteri, (2) penurunan denyut jantung, (3) penurunan motilitas dan sekresi gastrointestinal, (4) defekasi dan miksi, (5) dilatasi pupil, (6) pilo ereksi, (7) sekresi berbagai hormon hipofisis anterior terutama hormon kortikotropik dan gonadotropin (Guyton, 2015; Campbell, 2015).

Sinyal dari hipotalamus akan diteruskan melalui jalur HPA aksis. Hipotalamus akan mempengaruhi pituitary anterior dengan memproduksi corticoid releasing factor (CRF), sehingga berpengaruh pada penurunan produksi adreno corticosteroid hormon (ACTH)Perubahan disregulasi neurotransmitter juga bertanggungjawab pada perubahan emosi yang dialami oleh penderita. Beberapa neurotransmiter yang mengalami perubahan konsentrasi dalam otak yaitu GABA, serotonin dan norepineprin. Perubahan neurotransmiter akan berpengaruh pada jalannya

\footnotetext{
Rahma Elliya', Satria Baharuddin ${ }^{2 *}$, Dessy Hermawan'

'Program Studi llmu Keperawatan, Fakultas Kedokteran Universitas Mahalayati.

${ }^{2}$ Posyandu Lansia Puskesmas Kalibalagan Kabupaten Lampung Utara

Korespondensi Penulis: Satria Baharuddin. Email: satriabaharudddin@gmail.com
}

DOI: https://doi.org/10.33024/hjk.v15i1.1605 
Pengaruh terapi musik klasik (mozart) terhadap tekanan darah pada lansia dengan hipertensi

sinyal ke organ yang dituju. Jumlah GABA yang berlebihan dapat meningkatkan resiko penderita untuk mengalami stres atau keadaan tidak rileks. Setelah mengalami hipertensi, pada penderita umumnya ditemukan adanya peningkatan kadar kortisolSehingga penurunan kadar kortisol berpengaruh pada penurunan tekanan darah, denyut jantung dan frekuensi napas, serta menimbulkan respons emosi positif (Smeltzer, 2015).

Dalam penelitian ini ditemukan juga bahwa pada kelompok kontrol yaitu lansia yang hanya mendapat terapi Amlodipine rata-rata tekanan darah systole sebelum diberi Amlodipine adalah $163.9 \mathrm{mmHg}$ sedangkan rata-rata tekanan darah systole sesudah diberi Amlodipine adalah 152.1 $\mathrm{mmHg}$. Hal ini menunjukkan bahwa terapi Amlodipine juga menurunkan tekanan darah. Hal ini sesuai kegunaannya bahwa amlodipine adalah obat antihipertensi dan antiangina yang tergolong dalam obat antagonis kalsium golongan dihidropiridin (antagonis ion kalsium). Amlodipien bekerja dengan menghambat influks (masuknya) ion kalsium melalui membran ke dalam otot polos vaskular dan otot jantung sehingga mempengaruhi kontraksi otot polos vaskular dan otot jantung. Amlodipine menghambat influks ion kalsium secara selektif, di mana sebagian besar mempunyai efek pada sel otot polos vaskular dibandingkan sel otot jantung. Efek antihipertensi amlodipine adalah dengan bekerja langsung sebagai vasodilator arteri perifer yang dapat menyebabkan penurunan resistensi vaskular serta penurunan tekanan darah. Dosis satu kali sehari akan menghasilkan penurunan tekanan darah yang berlangsung selama 24 jam. Onset kerja amlodipine adalah perlahan-lahan, sehingga tidak menyebabkan terjadinya hipotensi akut. Sesudah pemberian dengan dosis terapeutik secara oral, amlodipine akan diabsorbsi dengan kadar puncak dalam darah sesudah 6-12 jam pemberian. Bioavailabilitas absolut antara $64 \%$ dan $80 \%$. Volume distribusi mencapai $21 \mathrm{~L} / \mathrm{kg}$. Absorbsi amlodipine tidak dipengaruhi oleh konsumsi makanan.

\section{SIMPULAN}

Dari 62 orang, adaperbedaan tekanan darah sistolik pada penderita hipertensi sedang antara kelompok intervensiterapi musik klasik (mozart) dan $\operatorname{kelompok} \operatorname{kontrol}(p$-value $=0,000) \cdot \mathrm{Ada}$ perbedaan tekanan darah diastolik pada penderita hipertensi sedang antara kelompok intervensi terapi musik klasik (mozart) dan kelompok( $p$ value $=0,016$ ).

\section{SARAN}

Sebaiknya bagi peneliti selanjutnya dapat menambah jumlah sampel yang lebih banyak dan teknik penelitian yang lebih baik, dengan memperhatikan variable confounding yang menjadi penghambat seperti konsumsi makanan bersantan, rokok dan kopi.

\section{DAFTAR PUSTAKA}

Arif, M. (2014). Kapita Selekta Kedokteran Edisi 3. Jilid 2.

Campbell, D. G. (2015). Efek mozart. Gramedia Pustaka Utama.

Dinas Kesehatan Propinsi Lampung, (2015). Profil Kesehatan. Dinkes Propinsi Lampung.

Guyton, A. C. (2015). Buku Teks Fisiologi Kedokteran, 11. EGC, Jakarta, 882-945.

Hikayati, H., Flora, R., \& Purwanto, S. (2014). Penatalaksanaan Non Fakmakologis Terapi Komplementer sebagai Upaya Untuk Mengatasi dan Mencegah Komplikasi pada Penderita Hipertensi Primer di Kelurahan Indralaya Mulya Kabupaten Ogan llir.

Kementrian Kesehatan Republik Indonesia, (2012). Gambaran Penyakit Tidak Menular di Rumah Sakit di Indonesia Tahun 2009 dan 2010. Buletin Jendela Data dan Informasi Kesehatan, 2(2), 1-14

\footnotetext{
Rahma Elliya', Satria Baharuddin ${ }^{2 *}$, Dessy Hermawan'

'Program Studi llmu Keperawatan, Fakultas Kedokteran Universitas Mahalayati.

${ }^{2}$ Posyandu Lansia Puskesmas Kalibalagan Kabupaten Lampung Utara

Korespondensi Penulis: Satria Baharuddin. Email: satriabaharudddin@gmail.com
}

DOI: https://doi.org/10.33024/hjk.v15i1.1605 
Pengaruh terapi musik klasik (mozart) terhadap tekanan darah pada lansia dengan hipertensi

Mahanani, A. (2013). Durasi pemberian terapi musik klasik mozart terhadap tingkat kecemasan pada anak. Skripsi, Universitas Jenderal Soedirman.

Mahatidanar, A. (2017). Pengaruh Musik Klasik Terhadap Penurunan Tekanan Darah pada Lansia Penderita Hipertensi. Agromedicine, 4(2), 264-268.

Masriadi, H. (2016). Epidemiologi Penyakit Tidak Menular. Jakarta: CV. Trans Info Media, Hal, 359-370.

Mulyadi, E. (2013). Pengaruh Musik Suara Alam Terhadap Tekanan Darah Ibu Hamil Di Polindes Pagar Batu Kecamatan Saronggi Kabupaten Sumenep. Wiraraja Medika, 3(1), 39.

Natalia, D. (2013). Terapi musik bidang keperawatan. Jakarta: Mitra Wacana Media.

Novita, D. (2012). Pengaruh terapi musik terhadap nyeri post operasi open reduction and internal fixation (orif) di RSUD DR. H. Abdul Moeloek Propinsi Lampung. Jurnal IImiah Kesehatan Keperawatan.(online).

Rahajeng, E., \& Tuminah, S. (2009). Prevalensi hipertensi dan determinannya di Indonesia. Majalah Kedokteran Indonesia, 59(12), 580587.
Salim, D. (2011). Psikologi Musik. Yogyakarta: Galangpress.

Sastra, L. (2011). Pengaruh terapi musik klasik (mozart) terhadap penurunan tekanan darah sistolik pada lansia dengan hipertensi di wilayah kerja Puskesmas Air Dingin Kecamatan Koto Tangah Padang tahun 2011.

Smeltzer, S. C., BARE, B. B., Hinkle, J., \& Cheever, K. B. (2015). Suddarth. Buku Ajar Keperawatan Medikal Bedah. EGC: Jakarta.

Suherly, M., \& Meikawati, W. (2012). Perbedaan tekanan darah pada pasien hipertensi sebelum dan sesudah pemberian terapi musik klasik di RSUD Tugurejo Semarang. Karya IImiah.

Tedjasukmana, P.(2012). Tata laksana hipertensi. CDK-192, 39(4)

Triyanto, E. (2014). Pelayanan keperawatan bagi penderita hipertensi secara terpadu. Yogyakarta: Graha IImu.

Yogiantoro, M. (2015). Buku ajar ilmu penyakit dalam. Edisi ke-7. AW Sudoyo et al., eds. Jakarta: Interna Publishing.

\footnotetext{
Rahma Elliya', Satria Baharuddin ${ }^{2 *}$, Dessy Hermawan'

'Program Studi llmu Keperawatan, Fakultas Kedokteran Universitas Mahalayati.

${ }^{2}$ Posyandu Lansia Puskesmas Kalibalagan Kabupaten Lampung Utara

Korespondensi Penulis: Satria Baharuddin. Email: satriabaharudddin@gmail.com

DOI: https://doi.org/10.33024/hjk.v15i1.1605
} 